Lu Li, Huajian Duan and Jun Qian*

\title{
Crystal structure of poly[bis $\left(\mu_{2^{-}}\right.$ 2,6-bis(1-imidazoly)pyridine- $\mathrm{k}^{2} N, N$ )- bis(thiocyanato-k ${ }^{1} N$ )copper(II)] dithiocyanate, $\mathrm{C}_{24} \mathrm{H}_{18} \mathrm{CuN}_{12} \mathrm{~S}_{2}$
}

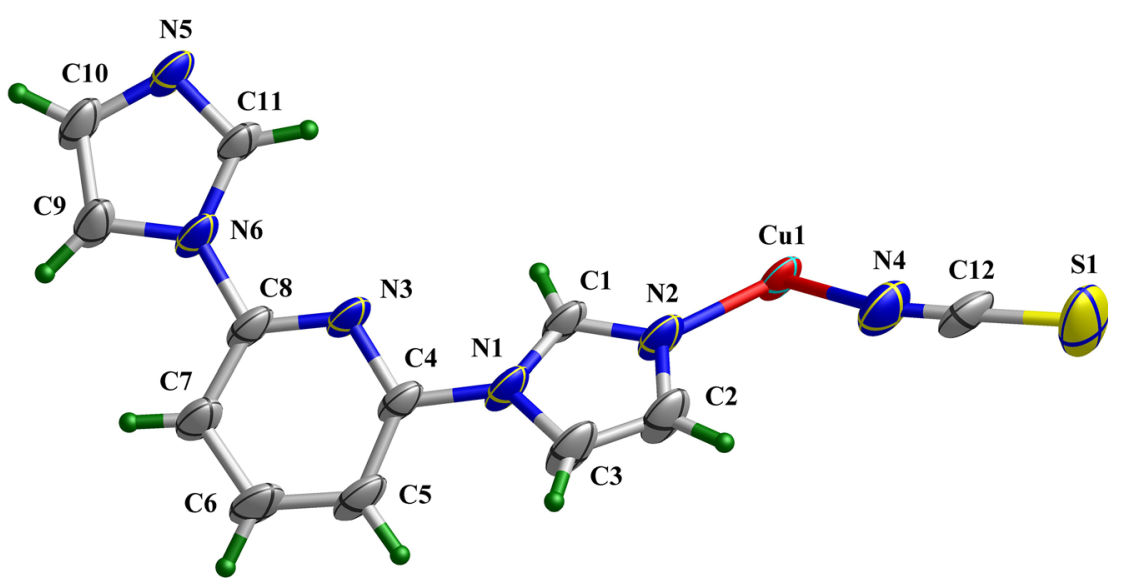

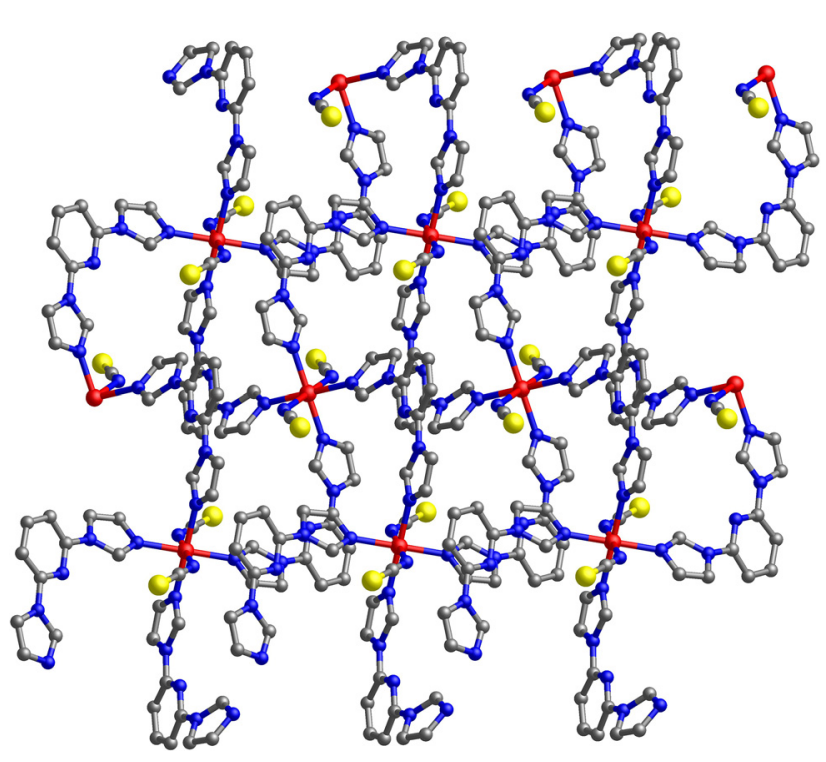

https://doi.org/10.1515/ncrs-2021-0369

Received September 21, 2021; accepted November 21, 2021; published online December 1, 2021

*Corresponding author: Jun Qian, School of Chemistry and Chemical Engineering, Jiangsu University, Zhenjiang, Jiangsu 212013, P. R. China, E-mail: junqian8203@ujs.edu.cn. https://orcid.org/ 0000-0003-1538-6068

Lu Li and Huajian Duan, School of Chemistry and Chemical Engineering, Jiangsu University, Zhenjiang, Jiangsu 212013, P. R. China

\begin{abstract}
$\mathrm{C}_{24} \mathrm{H}_{18} \mathrm{CuN}_{12} \mathrm{~S}_{2}$, monoclinic, $P 2_{1} / c$ (no. 4), $a=11.038$ (2) $\AA$, $b=8.9312(18) \AA, c=16.083(5) \AA, \beta=125.66(2)^{\circ}, \mathrm{V}=1288.2(6) \AA^{3}$, $Z=2, R_{g t}(F)=0.0265, w R_{\text {ref }}\left(F^{2}\right)=0.0974, \mathrm{~T}=293 \mathrm{~K}$.
\end{abstract}

CCDC no.: 2022261

The crystal structure is shown in the figure. Table 1 contains crystallographic data and Table 2 contains the list of the atoms including atomic coordinates and displacement parameters.

\section{Source of materials}

All the reagents were commercially available and used as received without further purification. About $13.5 \mathrm{mg}$ CuSCN $(0.1 \mathrm{mmol})$ and $10.3 \mathrm{mg} \mathrm{NH}_{4} \mathrm{SCN}(0.1 \mathrm{mmol})$ were dissolved in DMF ( $3 \mathrm{~mL}$ ) with strong stirring to obtain a colorless solution. Then, $42.2 \mathrm{mg}$ 2,6-bis(1-imidazoly)pyridine (2,6-BIP) $(0.2 \mathrm{mmol})$ was added to the mixture, which turns into the blue-green solution immediately. After filtration, $1 \mathrm{~mL}$ DMF and $5 \mathrm{~mL}$ acetonitrile were added to the upper layer of the filtrate as buffer solution and diffusion solution, sequentially. Green crystals were obtained after a week at room temperature in the dark with a yield of $38 \mathrm{mg}(64 \%$ based $\mathrm{Cu}$ ). Anal. Calcd. for $\mathrm{C}_{24} \mathrm{H}_{18} \mathrm{CuN}_{12} \mathrm{~S}_{2}$ : C, $47.87 \%$; $\mathrm{H}$, 3.01\%; N, 27.91\%. Found C, 48.02\%; H, 3.03\%; N, 27.76\%. IR (KBr, $\left.v / \mathrm{cm}^{-1}\right)$ : 2083(s), 2054(s), 1654(m), 1605(s), 1585(m), 
Table 1: Data collection and handling.

\begin{tabular}{|c|c|}
\hline Crystal: & Block, red \\
\hline Size: & $0.18 \times 0.15 \times 0.12 \mathrm{~mm}$ \\
\hline Wavelength: & Mo $K \alpha$ radiation $(0.71073 \AA)$ \\
\hline$\mu:$ & $1.05 \mathrm{~mm}^{-1}$ \\
\hline Diffractometer, scan mode: & Bruker APEX-II, $\varphi$ and $\omega$-scans \\
\hline$\theta_{\max }$, completeness: & $26^{\circ},>99 \%$ \\
\hline$N\left(h k l_{\text {measured }}, N(h k l)_{\text {unique }}, R_{\text {int }}:\right.$ & $6033,2496,0.027$ \\
\hline Criterion for $I_{\mathrm{obs}}, N\left(h k l_{\mathrm{gt}}\right.$ : & $I_{\text {obs }}>2 \sigma\left(I_{\text {obs }}\right), 2082$ \\
\hline$N(\text { param })_{\text {refined }}:$ & 179 \\
\hline Programs: & $\begin{array}{l}\text { Bruker programs [1], OLEX2 } \\
\text { [2], SHELX [3, 4], PLATON [5] }\end{array}$ \\
\hline
\end{tabular}

Table 2: Fractional atomic coordinates and isotropic or equivalent isotropic displacement parameters $\left(\AA^{2}\right)$.

\begin{tabular}{lrrrr}
\hline & $\boldsymbol{x}$ & $\boldsymbol{y}$ & $\boldsymbol{z}$ & $\boldsymbol{U}_{\text {iso }} / \boldsymbol{U}_{\text {eq }}$ \\
\hline Cu1 & 0.0000 & 0.0000 & 0.0000 & $0.03267(18)$ \\
S1 & $-0.32137(14)$ & $-0.04437(13)$ & $-0.37442(7)$ & $0.0776(4)$ \\
N1 & $0.2056(2)$ & $0.4126(2)$ & $0.12582(16)$ & $0.0324(5)$ \\
N2 & $0.0776(2)$ & $0.2157(2)$ & $0.03442(17)$ & $0.0361(5)$ \\
N3 & $0.2557(2)$ & $0.5153(2)$ & $0.27563(17)$ & $0.0311(5)$ \\
N4 & $-0.1542(3)$ & $0.0728(3)$ & $-0.1783(2)$ & $0.0544(7)$ \\
N6 & $0.2931(2)$ & $0.6057(2)$ & $0.42386(16)$ & $0.0335(5)$ \\
C1 & $0.1392(3)$ & $0.2831(3)$ & $0.1231(2)$ & $0.0329(6)$ \\
H1 & 0.1375 & 0.2469 & 0.1766 & $0.039^{*}$ \\
C2 & $0.1035(3)$ & $0.3070(3)$ & $-0.0227(2)$ & $0.0416(7)$ \\
H2 & 0.0709 & 0.2881 & -0.0896 & $0.050^{*}$ \\
C3 & $0.1829(3)$ & $0.4270(3)$ & $0.0325(2)$ & $0.0414(7)$ \\
H3 & 0.2160 & 0.5045 & 0.0118 & $0.050^{*}$ \\
C4 & $0.2990(3)$ & $0.5035(3)$ & $0.2145(2)$ & $0.0300(6)$ \\
C5 & $0.4265(3)$ & $0.5661(3)$ & $0.2326(2)$ & $0.0378(6)$ \\
H5 & 0.4539 & 0.5513 & 0.1884 & $0.045^{*}$ \\
N5 & $0.1602(2)$ & $0.5600(2)$ & $0.48272(17)$ & $0.0341(5)$ \\
C6 & $0.5110(3)$ & $0.6518(3)$ & $0.3199(2)$ & $0.0436(7)$ \\
H6 & 0.5972 & 0.6978 & 0.3348 & $0.052^{*}$ \\
C7 & $0.4700(3)$ & $0.6703(3)$ & $0.3851(2)$ & $0.0403(7)$ \\
H7 & 0.5256 & 0.7288 & 0.4438 & $0.048^{*}$ \\
C8 & $0.3416(3)$ & $0.5973(3)$ & $0.3591(2)$ & $0.0322(6)$ \\
C12 & $-0.2225(3)$ & $0.0252(3)$ & $-0.2593(2)$ & $0.0395(7)$ \\
C11 & $0.1728(3)$ & $0.5339(3)$ & $0.4079(2)$ & $0.0363(6)$ \\
H11 & 0.1080 & 0.4741 & 0.3514 & $0.044^{*}$ \\
C9 & $0.3593(3)$ & $0.6829(3)$ & $0.5149(2)$ & $0.0432(7)$ \\
H9 & 0.4438 & 0.7430 & 0.5459 & $0.052^{*}$ \\
C10 & $0.2767(3)$ & $0.6533(3)$ & $0.5499(2)$ & $0.0416(7)$ \\
H10 & 0.2956 & 0.6905 & 0.6104 & $0.050^{*}$ \\
\hline & & & &
\end{tabular}

1491(s), 1458(s), 1319(w), 1286(w), 1233(m), 1176(w), 1061(m), 1004(w) (pyridine: $\mathrm{C}=\mathrm{N}), 849(\mathrm{w}), 792(\mathrm{~m}), 743(\mathrm{w}), 653(\mathrm{~m})$.

\section{Experimental details}

The structure was solved by direct methods and refined using the SHELX software [3]. All of the hydrogen atoms were added using a riding model [4].

\section{Comment}

Coordination polymers (CPs) have received enormous interests because of their intriguing skeletal structures, as well as the potential applications in gas absorption [6], catalysis [7], magnetism [8, 9], photoluminescence [10-12] and so on. Consequently, considerable efforts in this field have been devoted to the design and syntheses of various kinds of CPs to obtain desirable properties [13]. To extend the types of $\mathrm{CPs}$, different rigid or flexible ligands have been extensively used in the preparation of $\mathrm{CPs}[14,15]$. In recent years, many CPs based on semi-rigid ligands such as bis(imidazole) derivatives have been reported $[16,17]$. From the view of structural chemistry, the hinged 2,6-BIP molecule is a typical semi-rigid ligand, in which the $\mathrm{C}-\mathrm{N}$ bonds between three rings can rotate to some extent. Therefore, the introduction of 2,6-BIP ligand can affect the spatial configuration of CPs and then modify the corresponding properties.

As shown in the upper part of the figure, the asymmetric unit of the title structure consists of a half $\mathrm{Cu}$ (II) cation (located on a center of symmetry), one 2,6-BIP molecule and one $\mathrm{SCN}^{-}$ion. The $\mathrm{Cu}$ (II) center is six-coordinated by six $\mathrm{N}$ atoms, in which two $\mathrm{N}$ atoms from $\mathrm{SCN}^{-}$ions and four from 2,6-BIP ligands, forming an octahedral configuration. The $\mathrm{Cu}-\mathrm{N}$ bond lengths are in the range of 2.016(2)-2.419(3) $\AA$, while the bond angles of $\mathrm{N}-\mathrm{Cu}-\mathrm{N}$ range from $87.80(9)$ to $180.0^{\circ}$. The connection between $\mathrm{Cu}(\mathrm{II})$ ions and 2,6-BIP ligands leads to a four-membered metal ring, and these rings are further extend to a two-dimensional network, exhibiting a four-connected sql topological structure (lower part of the figure). Due to the rotability of $\mathrm{C}-\mathrm{N}$ bond in 2,6-BIP ligand, the dihedral angles between the pyridine ring and two imidazole rings are $3.4^{\circ}$ and $35.6^{\circ}$, respectively, which resulting in the 2D structure of title $\mathrm{CP}$ to be helical.

Author contributions: All the authors have accepted responsibility for the entire content of this submitted manuscript and approved submission.

Research funding: This work was funded by the National Natural Science Foundation of China (grant no. 51602130). Conflict of interest statement: The authors declare no conflicts of interest regarding this article.

\section{References}

1. BRUKER. SAINT, APEX2 and SADABS; Bruker AXS Inc.: Madison, Wisconsin, USA, 2009.

2. Dolomanov O. V., Bourhis L. J., Gildea R. J., Howard J. A., Puschmann H. OLEX2: a complete structure solution, refinement and analysis program. J. Appl. Crystallogr. 2009, 42, 339-341. 
3. Sheldrick G. M. SHELXT - integrated space-group and crystalstructure determination. Acta Crystallogr. 2015, A71, 3-8.

4. Sheldrick G. M. Crystal structure refinement with SHELXL. Acta Crystallogr. 2015, C71, 3-8.

5. Spek A. L. Single-crystal structure validation with the program PLATON. J. Appl. Crystallogr. 2003, 36, 7-13.

6. Jiang X., Li Z., Zhai Y., Yan G., Xia H., Li Z. Porous coordination polymers based on azamacrocyclic complex: syntheses, solvent induced reversible crystal-to-crystal transformation and gas sorption properties. CrystEngComm 2014, 16, 805-813.

7. Paul A., Karmakar A., Guedes da Silva M. F. C., Pombeiro A. J. L. 1D $\mathrm{Zn}$ (II) coordination polymers as effective heterogeneous catalysts in microwave-assisted single-pot deacetalization-knoevenagel tandem reactions in solvent-free conditions. Catalysts 2021, 11, 90.

8. Wang Y. F., Li S. H., Ma L. F., Geng J. L., Wang L. Y. Syntheses, crystal structures, and magnetic studies of two cobalt(II) coordination polymers based on concurrent ligand extension. Inorg. Chem. Commun. 2015, 62, 42-46.

9. Qian J., Yoshikawa H., Humphrey M. G., Zhang J. F., Awaga K., Zhang $\mathrm{C}$. In situ formed $\left[\mathrm{M}(\mathrm{CN})_{9}\right](\mathrm{M}=\mathrm{W}, \mathrm{Mo})$ as a building block for the construction of two nona-cyanometalate-bridged heterometallic coordination polymers. CrystEngComm 2019, 21, 4363-4372.

10. Zhang J. F., Jia D., Humphrey M. G., Meng S. C., Zaworotko M. J., Cifuentes M. P., Zhang C. Ammonium-crown ether supramolecular cation-templated assembly of an unprecedented heterobicluster- metal coordination polymer with enhanced NLO properties. Chem. Commun. 2016, 52, 3797-3800.

11. Yang J. X., Qin Y. Y., Ye R. P., Zhang X., Yao Y. G. Employing mixedligand strategy to construct a series of luminescent $C d(I I)$ compounds with structural diversities. CrystEngComm 2016, 18, 8309-8320.

12. Heine J., Müller-Buschbaum K. Engineering metal-based luminescence in coordination polymers and metal-organic frameworks. Chem. Soc. Rev. 2013, 42, 9232-9242.

13. Leong W. L., Vittal J. J. One-dimensional coordination polymers: complexity and diversity in structures, properties, and applications. Chem. Rev. 2011, 111, 688-764.

14. Adeline Y. R., Katharina M. F. Coordination polymer networks with O- and N-donors: what they are, why and how they are made. Coord. Chem. Rev. 2006, 250, 2127-2157.

15. Xin L. Y., Liu G. Z., Li X. L., Wang L. Y. Structural diversity for a series of metal(II) complexes based on flexible 1,2-phenylenediacetate and dipyridyl-type coligand. Cryst. Growth Des. 2012, 12, 147-157.

16. Han M. L. Crystal structure of catena-poly[diaqua-bis (3-carboxy5-methoxybenzoato-kO)-(1,2-bis(imidazol-1-yl)ethane- $\left.\kappa^{2} N: N^{\prime}\right)$ cobalt(II)], $\mathrm{C}_{26} \mathrm{H}_{28} \mathrm{CoN}_{4} \mathrm{O}_{12}$, [Co $\left.\left(\mathrm{C}_{9} \mathrm{H}_{6} \mathrm{O}_{5}\right)_{2}\left(\mathrm{H}_{2} \mathrm{O}\right)_{2}\left(\mathrm{C}_{8} \mathrm{H}_{10} \mathrm{~N}_{4}\right)\right]$. Z. Kristallogr. NCS. 2019, 234, 617-618.

17. Son S. U., Park K. H., Kim B. Y., Chung Y. K. Construction of cylindrical nanotubular materials by self-assembly of $\mathrm{Co}(\mathrm{NCS})_{2}$ with bent-building blocks having diimidazole rings. Cryst. Growth Des. 2003, 3, 507-512. 